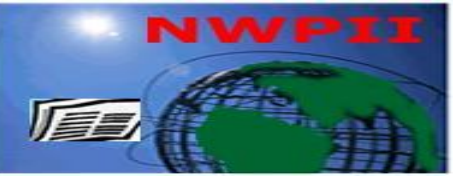

American Journal of Biomedical Sciences

ISSN: 1937-9080

nwpii.com/ajbms

\title{
Flow-injection Post-chemiluminescence Determination of Furazolidone in Animal Feeds
}

\author{
Xuegang Li, Jiwei Hu, Heyou Han*
}

College of Science, State Key Laboratory of Agricultural Microbiology, Huazhong Agricultural University, Wuhan 430070, PR. China

*Corresponding Author:

Dr. Heyou Han, professor

College of Science

State Key Laboratory of Agricultural Microbiology

Huazhong Agricultural University

Wuhan 430070, PR. China

Tel: +86-27-87288246;

Fax: +86-27-87288246.

E-mail: hyhan@mail.hzau.edu.cn

Received: 13 March 2009; | Revised: 13 May 2009; | Accepted: 18 May 2009

\begin{abstract}
The post-chemiluminescence (PCL) reaction was observed with the mixture solution after completion $\mathrm{CL}$ reaction of luminol- $\mathrm{H}_{2} \mathrm{O}_{2}$ in present of Furazolidone (FZD). A novel method for the determination of FZD was established by flow-injection PCL. The CL intensity responded linearly to the concentration of FZD in the range $1.0 \times 10^{-7}-1.0 \times 10^{-5} \mathrm{~g} \mathrm{~mL}^{-1}$, with a linear correlation of 0.9949 . The detection limit for FZD was $1.96 \times 10^{-8} \mathrm{~g} \mathrm{~mL}^{-1}(\mathrm{~S} / \mathrm{N}=3)$. The relative standard deviation (RSD) was $3.5 \%\left(\mathrm{n}=11, c=1.0 \times 10^{-6} \mathrm{~g} \mathrm{~mL}^{-1}\right)$. The proposed method has been applied to the determination of FZD in animal feeds and the results were consistent with those obtained by the HPLC-UV method. A possible mechanism for the PCL reaction was also discussed by the investigation of CL kinetic characteristics, CL spectra and UV-Vis absorption spectra.
\end{abstract}

Keywords: Post chemiluminescence; furazolidone; luminol.

\section{Introduction}

Furazolidone (FZD), N-[5-nitro-2-furfurylidene -3-amino]-2-oxazolidinone (Fig. 1), is one of the nitrofuran antibiotic drugs, which was widely used in food animal production because of its broadspectrum antimicrobial activity and pharmacokinetic properties. It has been also used as growth promoters in the pig production, poultry and fish sector. Due to concerns about its carcinogenicity and mutagenicity, FZD has been banned from use in food animal production in the EU in 1995 [1, 3]. Despite the potentially harmful effects on human health, it is still illegally and widely used in many countries because it is cheap and effective. 
FZD compound was usually administered to animals by means of medicated feeds or at drinking water. The analysis of FZD needs to be based on the detection of FZD marker residue. Studies using ${ }^{14} \mathrm{C}$-labeled FZD have shown that protein-bound metabolites are formed in tissues [4,5]. FZD metabolites are detectable for several weeks after administration. For this reason, the FZD metabolites are determined in animal tissues, whereas farm animal feeds may be checked for the presence of the FZD parent compounds.

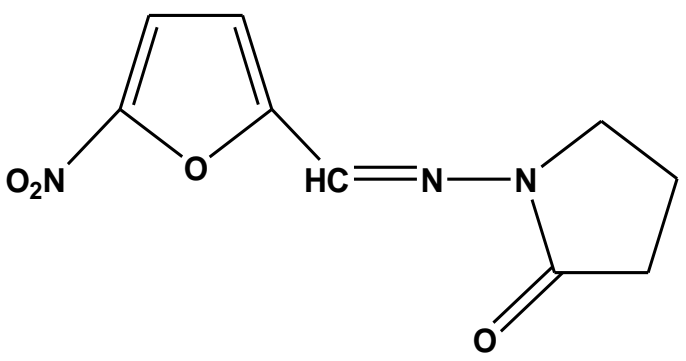

Figure 1. Chemical structures of the FZD.

Several methods have been released for the detection of FZD in feeds and biological matrices by TLC [6], HPLC-ECD [7], HPLC-UV [8,9] and LC-MS [10]. However, the majority procedures of LC-UV available for FZD feed control, shown limits of quantification around $1 \mathrm{mg} \mathrm{kg}^{-1}$, is not suitable for FZD screening procedures [11]. Furthermore, these procedures available for FZD feed control are time-consuming or costly. Since the main difficulty in the determination of FZD is its instability due to sensitivity to light [12], there is now an urgent need for a rapid, simple, and sensitive determination method for FZD at low concentrations in animal feed, in order to satisfy needs on feed control.

Chemiluminescence (CL) analysis has received much attention for the analysis of organic species in a variety of fields for its high sensitivity, wide dynamic range and inexpensive instrumentation [13-14]. However, the CL signal of normal CL systems containing FZD was relatively weak. Post-chemiluminescence (PCL) as a peculiar CL phenomenon, had been reported by Lu JR's group [15-18]. We found the stronger signal of FZD was detected in PCL system.
This paper describes a novel PCL method for detection of FZD residues. The PCL phenomenon of FZD in $\mathrm{H}_{2} \mathrm{O}_{2}$-luminol system was discovered and the $C L$ reaction was investigated. The possible mechanism of the CL reaction was discussed. A new method for the determination of FZD was established combining the CL reaction with the flow injection technique. The present paper is the first report of a simple, cost-effective and fast flow injection CL method to determine the FZD in farm animal feed.

\section{Experimental}

\subsection{Apparatus}

The IFFM-D flow injection CL analyzer (Xi'an Remex Electronic Instrument High-Tech Ltd., China) was equipped with an automatic injection system and a detection system. The schematic diagram of the CL flow system employed is shown in Fig. 2. PTFE tube $(0.8 \mathrm{~mm}$ i.d.) was used to connect all of the components in the flow system. The flow cell was a coil of glass tube that positioned in front of the detection window of the PMT. The CL signal was treated with a personal computer. The CL spectra were acquired with Perkin Elmer Model LS-55 luminescence spectrometer (the light was cut off). The absorption spectra were acquired on a Thermo Nicolet Corporation Model evolution 300 UVVisible spectrometer.

\subsection{Chemicals and solutions}

Stock solution $\left(1.0 \times 10^{-2} \mathrm{~mol} \mathrm{~L}^{-1}\right)$ of luminol was prepared by dissolving luminol (Sigma) in $\mathrm{NaOH}\left(0.1 \mathrm{~mol} \mathrm{~L}^{-1}\right)$ without purification. Working solutions of luminol were prepared by diluting the stock solution. Working solutions of $\mathrm{H}_{2} \mathrm{O}_{2}$ were prepared fresh daily from $30 \%$ (v/v) $\mathrm{H}_{2} \mathrm{O}_{2}$ (Shanghai Chemical Reagent Co., Ltd.). HPLC grade methanol, acetonitrile, dimethylformamide (DMF), hexane, and ethyl acetate were purchased from Shanghai Chemical Reagent Co., Ltd. FZD was purchased from Sigma-Aldrich (Germany). The standard solution of FZD $\left(1.00 \times 10^{-4} \mathrm{~g} \mathrm{~mL}^{-1}\right)$ was prepared by initially dissolving $0.0100 \mathrm{~g}$ FZD with DMF and diluting to $100 \mathrm{~mL}$ with water. More dilute solutions were prepared from the stock solution by appropriate dilution with water. 
All FZD solutions were stored in a refrigerator and protected from light. All other solvents and reagents, as well as Lichrolut $\mathrm{EN}(\mathrm{C} 18,500 \mathrm{mg}, 3$ $\mathrm{mL}$ ) solid-phase extraction (SPE) cartridges were purchased from Merck (Darmstadt, Germany). Deionized and distilled water was used through out the whole experiment.

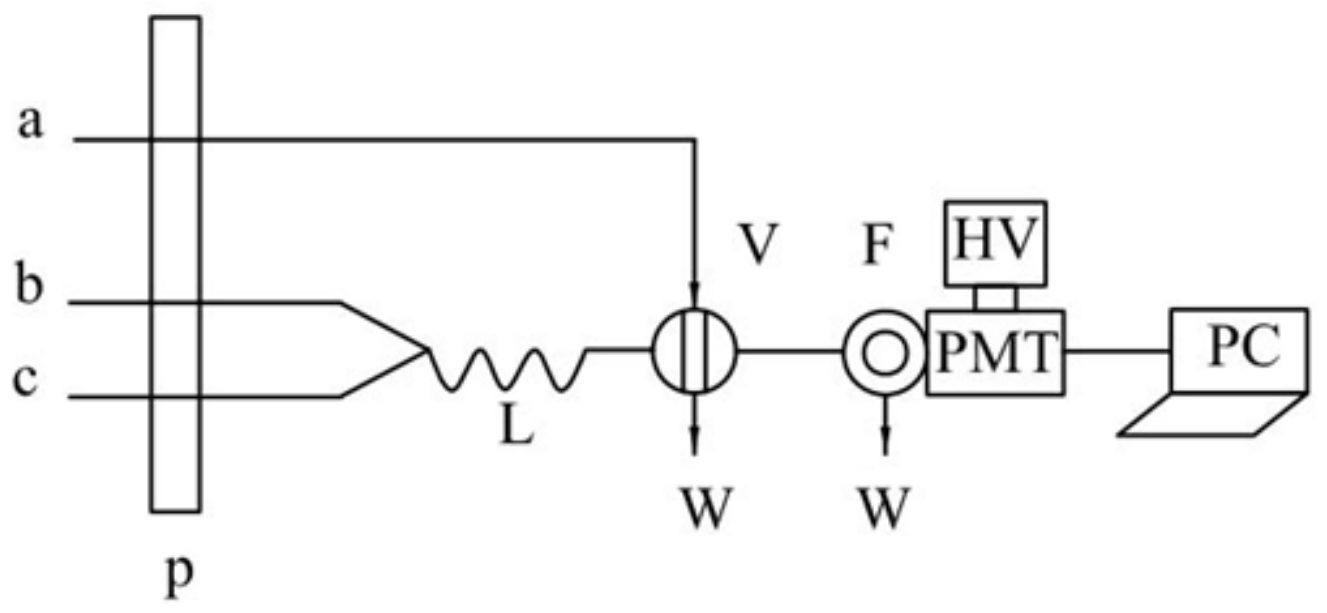

Figure 2. Schematic diagram of CL flow system.(a)FZD solution; (b) $\mathrm{H}_{2} \mathrm{O}_{2}$ solution; (c) Luminol solution; (P) peristaltic pump; (L) mixing tube; (V) injection valve; (W) waste; (F) flow cell; (HV) high voltage; (PMT) Photomultiplier tube; (PC) personal computer.

\subsection{Samples and sample preparation}

The animal feed samples were commercial feeds available on the local markets (Wuhan, China).

$0.1 \mathrm{~g}$ of the animal feed spiked with a 0.25 $\mathrm{mL}$ of FZD solution (of suitable concentration) was prepared by adding $1.0 \mathrm{~mL}$ of the ultrapure water to the feed sample, and then the sample was transferred into a $2 \mathrm{~mL}$ centrifuge tube with a thread lock. The tube was vigorously shaken in a mechanical shaker for $15 \mathrm{~min}$ and then centrifuged $(6000 \mathrm{~g})$ for $5 \mathrm{~min}$. The precipitation was treated with $1.0 \mathrm{~mL}$ of acetonitrile, agitated for $10 \mathrm{~min}$ by the mechanical shaker and centrifuged for $5 \mathrm{~min}$. The two supernatant extracts were transferred again to the tube and the combined extracts were then ready for solid-phase extraction. The SPE cartridges were conditioned with the distilled water $(3.0 \mathrm{~mL})$ and acetonitrile $(3.0 \mathrm{~mL})$ solvent was passed before the sample. The sample was loaded onto the cartridge. The loaded cartridge was washed with the washing solvent (hexane 5.0 $\mathrm{mL}$ ) and the analytes were selectively eluted with the elution solvent (ethyl acetate $5.0 \mathrm{~mL}$ ) into a glass tube. The residue obtained by evaporated to dryness under a nitrogen stream. The tube is removed immediately after drying and the solution reconstituted with $1.0 \mathrm{~mL}$ of DMF. For the determination procedure prepare a blank under the same conditions but without FZD spiking.

\subsection{PCL procedure}

Flow tubes were connected with $\mathrm{H}_{2} \mathrm{O}_{2}$ solution, luminol solution and FZD solution, respectively. $\mathrm{H}_{2} \mathrm{O}_{2}$ stream was merged with luminol stream through a Y-piece. When the baseline was stable, FZD solution was injected into the merged steam of $\mathrm{H}_{2} \mathrm{O}_{2}$-luminol solution by injection valve. The CL intensity (peak height) was used as the quantitative criterion.

\section{Results and Discussion}

\subsection{The PCL behavior of $\mathrm{FZD}$ in $\mathrm{H}_{2} \mathrm{O}_{2}$-luminol system}

Kinetic characteristics of the CL reactions were examined using the static measuring system of the IFFM-D multifunction CL analyzer. The CL intensity-time curve was shown in Fig. 3. When $5.0 \times 10^{-3} \mathrm{~mol} \mathrm{~L}^{-1}$ of $\mathrm{H}_{2} \mathrm{O}_{2}$ solution $(1.0 \mathrm{~mL})$ was 
injected into $3.0 \times 10^{-5} \mathrm{~mol} \mathrm{~L} \mathrm{~L}^{-1}$ of Luminol solution $(1.0 \mathrm{~mL})$, a CL reaction was initiated immediately (peak 1). After $500 \mathrm{~s}$ approximately, the CL reaction terminated and the CL signal declined to baseline. Subsequently, another stronger CL reaction (peak 2) was initiated when $1.0 \times 10^{-4} \mathrm{~g}$ $\mathrm{mL}^{-1}$ of FZD solution $(1.0 \mathrm{~mL})$ was injected into above reaction mixture. The $\mathrm{CL}$ reaction terminated and the CL signal declined to baseline again after $40 \mathrm{~s}$ approximately.

Under the same condition, CL signal was not detected by using the blank solution instead of the FZD solution. The experiments showed that the reaction initiated by FZD solution in the $\mathrm{H}_{2} \mathrm{O}_{2}$ luminol system was a post CL reaction.

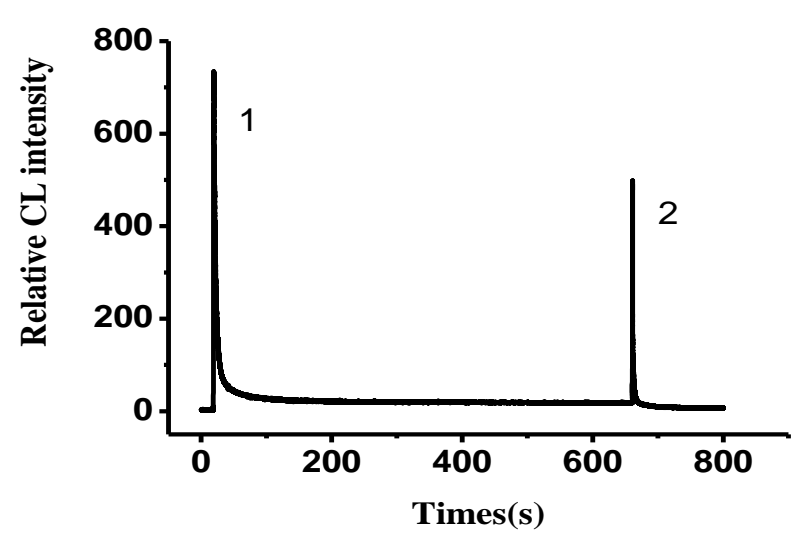

Figure 3. Kinetic curve of the $\mathrm{CL}$ reaction. (1) $5.0 \times 10^{-3} \mathrm{~mol} \mathrm{~L}^{-1}$ of $\mathrm{H}_{2} \mathrm{O}_{2}$ solution $(1.0 \mathrm{~mL})$ was injected into $3.0 \times 10^{-5} \mathrm{~mol} \mathrm{~L}^{-1}$ of Luminol solution $(1.0 \mathrm{~mL})$; (2) $1.0 \times 10^{-4} \mathrm{~g} \mathrm{~mL}^{-1}$ of FZD solution $(1.0 \mathrm{~mL})$ was injected into above reaction mixture.

\subsection{Optimization of experimental conditions}

Since it was the PCL reaction caused by FZD added in $\mathrm{H}_{2} \mathrm{O}_{2}$-luminol system, the $\mathrm{CL}$ reaction between $\mathrm{H}_{2} \mathrm{O}_{2}$ and luminol must react adequately in flow injection analysis (FIA) system before initiating the latter CL reaction. For this purpose, a mixing tube (L) $(0.8 \mathrm{~mm}$ i.d.) was connected between the Y-piece and the injection valve (Fig. 2 ). If the mixing tube were too short, $\mathrm{H}_{2} \mathrm{O}_{2}$ and luminol would react deficiently and the background would be too high. If the tube were too long, the post CL signal would be too weak. The length of the mixing tube was examined in the range $20-120 \mathrm{~cm}$ when the flow rate of each solution was fixed at $1.2 \mathrm{~mL} \mathrm{~min}{ }^{-1}$. The test showed that the optimal length of mixing tube was $75 \mathrm{~cm}$.

The PCL was affected by the $\mathrm{pH}$ of luminol solution. The maximal PCL signal was observed when the Concentration of Sodium hydroxide in luminol solution was $0.01 \mathrm{~mol} \mathrm{~L}^{-1}$.

The effect of luminol concentration on the PCL intensity was investigated from $1.0 \times 10^{-6}$ to $1.0 \times 10^{-5} \mathrm{~mol} \mathrm{~L}^{-1}$. The strongest PCL intensity was achieved when the concentration of luminol was $2.0 \times 10^{-6} \mathrm{~mol} \mathrm{~L}^{-1}$. Thus, $2.0 \times 10^{-6} \mathrm{~mol} \mathrm{~L}^{-1}$ was selected as the optimum concentration of luminol solution.

The effect of $\mathrm{H}_{2} \mathrm{O}_{2}$ concentration on the PCL intensity was studied in the range of $1.0 \times 10^{-5}$ $2.0 \times 10^{-4} \mathrm{~mol} \mathrm{~L}^{-1}$. The maximal PCL signal was obtained when the concentration of $\mathrm{H}_{2} \mathrm{O}_{2}$ solution was $1.0 \times 10^{-4} \mathrm{~mol} \mathrm{~L}^{-1}$.

\subsection{Analytical characteristics}

Under the optimum conditions, the relation between the CL intensity and the concentration of FZD was examined. The linear range of the method was $1.0 \times 10^{-7}$ to $1.0 \times 10^{-5} \mathrm{~g} \mathrm{~mL}^{-1}$, with a linear regression equation of $\mathrm{I}=4.57 \mathrm{c}+4.71$ $(r=0.9949)$, where $\mathrm{I}$ is the CL intensity (relative unit) and $\mathrm{c}$ is the concentration of FZD $\left(10^{-7} \mathrm{~g}\right.$ $\left.\mathrm{mL}^{-1}\right)$. RSD was $3.5 \%$ for 11 independent determinations of $1.0 \times 10^{-6} \mathrm{~g} \mathrm{~mL} \mathrm{~mL}^{-1}$ FZD. According to the suggestions of IUPAC, the measured detection limit of the method was $1.96 \times 10^{-8} \mathrm{~g} \mathrm{~mL}^{-1}$ FZD.

\subsection{Interference}

The effect of various components concurrently presented in animal feeds, especially carbohydrate and metal ions, on the determination of FZD by described method was investigated.

Under the optimum conditions, the interference tests were examined. A foreign species was considered not to interfere if it caused a relative error $<5 \%$ during the determination of $1.0 \times 10^{-6} \mathrm{~g} \mathrm{~mL}^{-1}$ of FZD solution. The tolerable concentration ratios of foreign species to $1.0 \times 10^{-6}$ $\mathrm{g} \mathrm{mL}^{-1}$ of FZD was over 1000-fold for $\mathrm{Na}^{+}, \mathrm{SO}_{4}{ }^{2-}$, $\mathrm{K}^{+}, \mathrm{Cl}^{-} ; 500$-fold for $\mathrm{Pb}^{2+}, \mathrm{Ca}^{2+}, \mathrm{Mg}^{2+}, \mathrm{CO}_{3}{ }^{2-} ; 100-$ fold for $\mathrm{Mg}^{2+}, \mathrm{Al}^{3+}, \mathrm{Ni}^{2+}, \mathrm{NH}_{4}^{+}$, glucose, lactose , 
soluble starch , fructose, maltose; 10 -fold for $\mathrm{Cr}^{3+}$, $\mathrm{Zn}^{2+}, \mathrm{Fe}^{2+}$.

\subsection{Sample analysis}

In order to validate the utility of the proposed method in a real sample, porcine feed samples were measured according to the method mentioned in Section 2.4. The FZD in porcine feed specimens was determined by the proposed method. As shown in Tables 1, the recoveries were calculated and the results were comparable with the HPLC-UV method [8]. The test was repeated three times per concentration. As show in Table 1, the recoveries of FZD were in the range of $82-87 \%$ at three levels in the above samples. $R S D$ was below $6 \%(\mathrm{n}=3)$. The results imply good agreement between FZD concentrations determined by two methods and prove the reliability of the PCL for the determination of real samples.

Table 1. The determination of FZD in animal feed. $(\mathrm{N}=3)$

\begin{tabular}{|c|c|c|c|c|c|c|c|}
\hline \multirow[b]{2}{*}{ Sample } & \multirow{2}{*}{$\begin{array}{c}\text { fortified } \\
\text { level } \\
\text { (ug/mL) }\end{array}$} & \multicolumn{2}{|c|}{ FZD found ${ }^{\mathrm{a}}(\mathrm{ug} / \mathrm{mL})$} & \multirow{2}{*}{$\begin{array}{c}\text { RSD } \\
(\%)\end{array}$} & \multirow{2}{*}{$\begin{array}{l}\text { Added } \\
(\mathrm{ug} / \mathrm{mL})\end{array}$} & \multirow{2}{*}{$\begin{array}{l}\text { Recovered } \\
\text { (ug/mL) }\end{array}$} & \multirow{2}{*}{$\begin{array}{c}\text { Recovery } \\
(\%)\end{array}$} \\
\hline & & PCL method & HPLC method & & & & \\
\hline 1 & 0.50 & $0.42 \pm 0.023$ & $0.45 \pm 0.021$ & 5.47 & 1.00 & 0.82 & 82 \\
\hline 2 & 1.00 & $0.91 \pm 0.023$ & $0.92 \pm 0.027$ & 2.55 & 1.00 & 0.87 & 87 \\
\hline 3 & 5.00 & $4.76 \pm 0.163$ & $4.79 \pm 0.143$ & 3.42 & 1.00 & 0.84 & 84 \\
\hline
\end{tabular}

${ }^{\mathrm{a}}$ Mean \pm S.D.

\subsection{Possible reaction mechanism}

An important process of studying the CL mechanism is to ascertain the luminant of the $\mathrm{CL}$ reaction. The CL spectra of the CL reactions were drawn (Fig. 4) by placing and exchanging the interference filters $(400-750 \mathrm{~nm})$ before the signal window of the BPCL-2 ultra-weak luminescence analyzer. A peak appeared at $425 \mathrm{~nm}$ when $\mathrm{H}_{2} \mathrm{O}_{2}$ and luminol were mixed (Fig. 4a). The same spectrum was obtained when FZD was injected into the mixing solution of $\mathrm{H}_{2} \mathrm{O}_{2}$ and luminol solution (Fig. 4b). The maximum emission wavelengths were both $425 \mathrm{~nm}$, which suggested that the two reactions have the same illuminant, the 3-aminophthalate ion (3-AP) [19, 20].

The absorption spectra of FZD solution and the mixtures of FZD and $\mathrm{H}_{2} \mathrm{O}_{2}$ solution were scanned (Fig. 5). It was observed that the specific absorptance peak in UV-vis spectra of FZD disappeared, which indicated that FZD was oxidized when $\mathrm{H}_{2} \mathrm{O}_{2}$ was added.

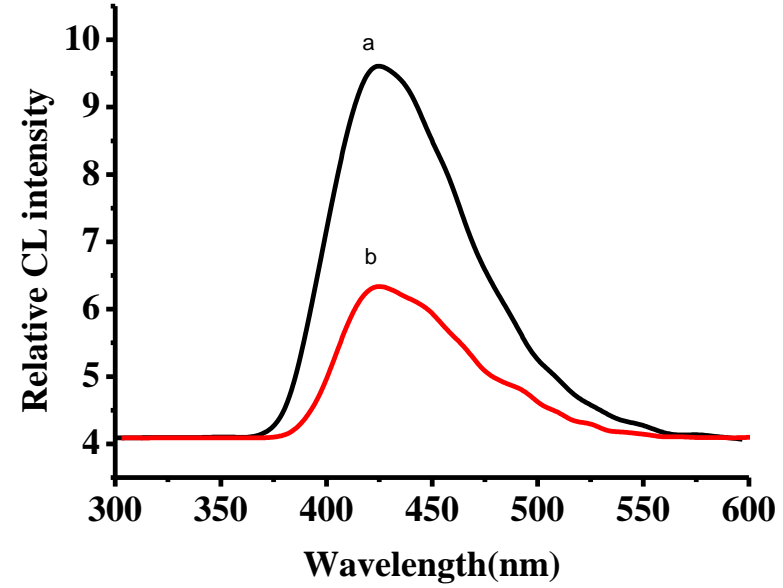

Figure 4. CL Spectra. a, $\mathrm{H}_{2} \mathrm{O}_{2}$ solution $\left(1.0 \times 10^{-4}\right.$ $\mathrm{mol} / \mathrm{l})$ +luminol solution $\left(2.0 \times 10^{-5} \mathrm{~mol} / \mathrm{l}\right)$; b, $\mathrm{H}_{2} \mathrm{O}_{2}$ solution $\left(1.0 \times 10^{-4} \mathrm{~mol} / \mathrm{l}\right)+$ luminol solution $\left(2.0 \times 10^{-5} \mathrm{~mol} / \mathrm{l}\right)+\mathrm{FZD} \operatorname{solution}(5.0 \times$ $\left.10^{-5} \mathrm{~g} / \mathrm{mL}\right)$; 


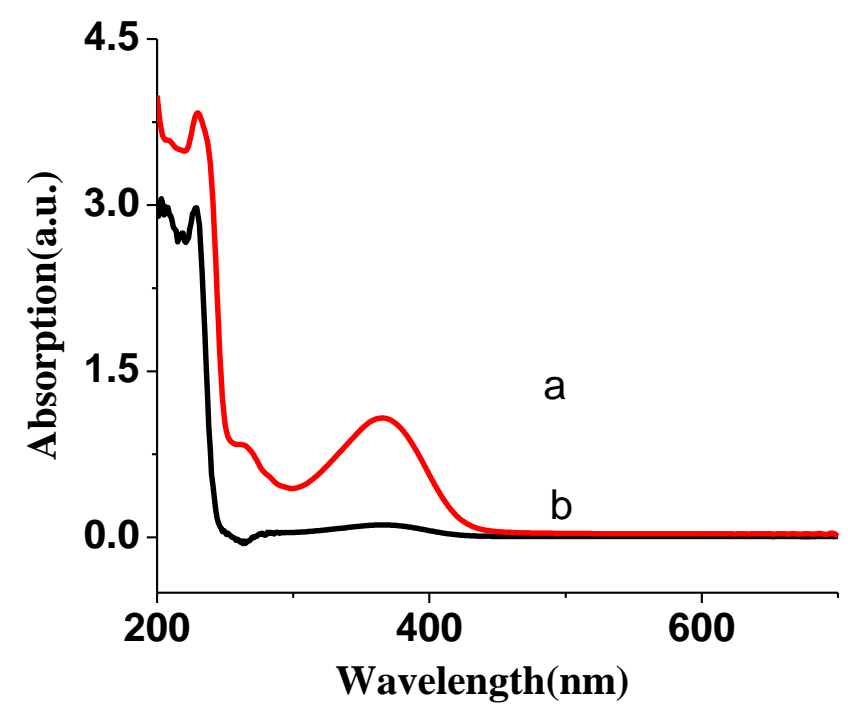

Figure 5. UV-vis spectra of FZD. a. FZD solution $\left(5.0 \times 10^{-5} \mathrm{~g} / \mathrm{mL}\right) ; \quad$ b. FZD $\operatorname{solution}(5.0 \times$ $\left.10^{-5} \mathrm{~g} / \mathrm{mL}\right)+\mathrm{H}_{2} \mathrm{O}_{2}$ solution $\left(1.0 \times 10^{-4} \mathrm{~mol} / \mathrm{l}\right)$.

Under the optimum conditions, the concentration of $\mathrm{H}_{2} \mathrm{O}_{2}\left(2.0 \times 10^{-5} \mathrm{~mol} \mathrm{~L}^{-1}\right)$ was much higher than that of luminol $\left(4.0 \times 10^{-6} \mathrm{~mol} \mathrm{L^{- }}\right.$ $\left.{ }^{1}\right)$. This result showed that excess $\mathrm{H}_{2} \mathrm{O}_{2}$ was necessary.

According to the test results above, the mechanism of the CL reaction of FZD in $\mathrm{H}_{2} \mathrm{O}_{2}$ and luminol system can be interpreted as: $\mathrm{H}_{2} \mathrm{O}_{2}$ oxidized luminol producing 3-AP at an excited state $\left(3-\mathrm{AP}^{*}\right)$. The $3-\mathrm{AP}^{*}$ came back to the ground state, accompanied by CL $(\max =425 \mathrm{~nm})$. When FZD was added to the resultant solutions of $\mathrm{H}_{2} \mathrm{O}_{2}$-luminol reaction, it was oxidized by $\mathrm{H}_{2} \mathrm{O}_{2}$ and released energy. 3-AP in the solution absorbed the energy and was excitated again, accompanied by CL.

The mechanism can be simply described as follows:

Luminol $+\mathrm{H}_{2} \mathrm{O}_{2}+\mathrm{OH}^{-} \rightarrow 3-\mathrm{AP}^{*} \rightarrow 3-\mathrm{AP}+h v$

$\mathrm{FZD}+\mathrm{H}_{2} \mathrm{O}_{2}+\mathrm{OH}^{-} \rightarrow$ FZD-oxide +energy $(\mathrm{E})$

$3-\mathrm{AP}+\mathrm{E} \rightarrow 3-\mathrm{AP}^{*} \rightarrow 3-\mathrm{AP}+h v \quad(\lambda \max =425 \mathrm{~nm})$

\section{Conclusion}

In this paper, a novel flow injection CL method for the determination of FZD was established based on the PCL reaction. The results suggest that this PCL is a simple, cost-effective Am. J. Biomed. Sci. 2009, 1(3), 260-266; doi: 10.5099/aj090300260 and fast method suitable for the detecting of FZD in feeding stuffs. The application of the PCL method to other analytes, especially more nitrofuran antibacterial compounds, and the mechanism of the PCL are under further investigation.

\section{Acknowledgments}

The authors gratefully acknowledge the support for this research by National Natural Science Foundation of China (20675034), Program for New Century Excellent Talents in Chinese Ministry of Education (NCET-05-0668), Nature Science Foundation from Hubei Province of China (2008CDB037) and The China Postdoctoral Science Foundation (20070410947).

\section{References}

1. Ali, B. H. Pharmacological, therapeutic and toxicological properties of furazolidone: some recent research, Veterinary Research Communications, 1999, 23(6), 343-360.

2. Auro, A.; Sumano, H.; Ocampo, L.; Barragan, A. Evaluation of the carcinogenic effects of furazolidone and its metabolites in two fish species. The Pharmacogenomics Journal, 2004, 4 (1), 24-28.

3. Commission regulation (EC) $1442 / 95$ of 26 June 1995 amending Annexes I, II, III and IV to Regulation (EEC) No 2377/90 laying down a Community Procedure for the establishment of maximum residue limits of veterinary medicinal products in foodstuffs of animal origin, Official Journal of the European Communities, 1995, L143, 26-30.

4. Hoogenboom, L.A.P.; Berghmans, M.C.J.; Polman, T.H.G.; Parker, R.; Shaw, I.C. Depletion of protein-bound furazolidone metabolites containing the 3-amino-2oxazolidinone side-chain from liver, kidney and muscle tissues from pigs, Food Additives and Contaminants, 1992, 9(6),623-630.

5. David W. Gottschall, Richard Wang.

Depletion and Bioavailability of [14C]Furazolidone Residues in Swine Tissues, Journal of Agricultural and Food Chemistry, 1995, 43(9), 2520-2525.

(C) 2009 by NWPII. All rights reserved. 
6. Sherma, J. Thin-layer chromatography in food and agricultural analysis, Journal of

Chromatography A, 2000, 880(1-2), 129 -147.

7. Galeano, D.T.; Guiberteau, C.A.; Acedo, V.M.I.; Correa, C.A.; Salinas, F. Determination of nitrofurantoin, furazolidone and furaltadone in milk by high-performance liquid chromatography with electrochemical detection, Journal of Chromatography A, 1997, 764(2), 243-248.

8. Pietruszka,K.; Olejnik,M.; Sell, B. Development and validation of a liquid chromatography method for the determination of nitrofurans in water, Bulletin of the Veterinary Institute in Pulawy, 2007, 51(2), 267-270.

9. Lin, S.-Y.; Jeng S.-L. High-performance liquid chromatographic determination of carbadox, olaquindox,furazolidone, nitrofurazone, and nitrovin in feed, Journal of Food Protection,2001, 64(8), 1231-1234.

10. Conneely, A.; Nugent, A.; O'Keeffe, M.; Mulder, P.P.; Rhijn, J. Isolation of bound residues of nitrofuran drugs from tissue by solid-phase extraction with determination by liquid chromatography with UV and tandem mass spectrometric detection, Analytica Chimica Acta ,2003, 483(1-2), 91-98.

11. Barbosa, J.; Moura, S.; Barbosa, R.; Ramos, F.; da Silveira, M.I.N. Determination of nitrofurans in animal feeds by liquid chromatography-UV photodiode array detection and liquid chromatographyionspray tandem mass spectrometry, Analytica Chimica Acta 2007, 586(1-2),359-365.

12. McCracken,R.J.; Spence, D.E.; Floyd, S.D.; Kennedy, D.G. Evaluation of the residues of furazolidone and its metabolite, 3-amino-2oxazolidinone (AOZ), in eggs, Food Additives \& Contaminants ,2001, 18(11), 954-959.

13. Yang, P.; Li, Y.-X.; Wang, P.; Wang, L. A sensitive inhibition chemiluminescence method for the determination of trace tannic acid using the reaction of luminol-hydrogen peroxide catalysed by tetrasulphonated manganese phthalocyanine, Luminescence, 2007, 22(1), 46-52.

14. King, D.W.; Cooper, W.J.; Rusak, S.A.; Peake, B.M.; Kiddle, J.J.; O'Sullivan, D.W.; Melamed, M.L.; Morgan, C.R.; Theberge, S.M. Flow injection analysis of $\mathrm{H}_{2} \mathrm{O}_{2}$ in natural waters using acridinium ester chemiluminescence: method development and optimization using a kinetic model, Analytical Chemistry, 2007,79(11), 4169-4176.

15. Sun, S.-W.; Lu, J.-R. Flow-injection post chemiluminescence determination of atropine sulfate, Analytica Chimica Acta , 2006, 580(1) , $9-13$.

16. Zhang, H.-Z.; Nie, F.; Lu, J.-R. Postchemiluminescence method of the determination of loperamide hydrochloride in human plasma and pharmaceutical by using dichlorofluorescein as chemiluminescence reagent, Analytical Letters. 2007, 40 (18), 3405-3416.

17. Bai, H.; Nie, F.; Lu, J.-R. Postchemiluminescence phenomenon of NBSLuminol reactions and their applications to flow injection analysis of piroxicam, Analytical Sciences, 2007, 23(11), 1301-1304.

18. Ma, M.-Y.; Lu, J.-R. Investigation of Postchemiluminescence Reaction in Potassium Periodate-luminol System, Chemical journal of Chinese universities, 2007, 28(3), 436-440.

19. Safavi, A; Karimi, MA. Flow injection determination of cationic surfactants by using $\mathrm{N}$-bromosuccinimide and $\mathrm{N}$-chlorosuccinimide as new oxidizing agents for luminol chemiluminescence, Analytica Chimica Acta, 2002, 468(1), 53-56.

20. Safavi, A; Karimi, MA; Nezhad, MR. Flow injection determination of isoniazid using $\mathrm{N}$ bromosuccinimide- and N-chlorosuccinimideluminol chemiluminescence systems, Journal of Pharmaceutical and Biomedical Analysis, 2003,30(5),1499-1506. 